\title{
A Parametric Study and Optimization of an Air Conditioning System for a Heat-Loaded Room
}

\author{
Qinghe Yao (D), ${ }^{1}$ Hang Bai, ${ }^{1}$ Trevor Hocksun Kwan, ${ }^{1}$ and Kiwamu Kase ${ }^{2}$ \\ ${ }^{1}$ School of Engineering, Sun Yat-Sen University, 510275, Guangzhou, China \\ ${ }^{2}$ Advanced Photonics Technology Development Group, RIKEN, 2-1 Hirosawa, Wako, Saitama 351-0198, Japan \\ Correspondence should be addressed to Qinghe Yao; yaoqhe@mail.sysu.edu.cn
}

Received 15 June 2018; Revised 24 August 2018; Accepted 4 September 2018; Published 30 September 2018

Academic Editor: Kwang-Yong Kim

Copyright (c) 2018 Qinghe Yao et al. This is an open access article distributed under the Creative Commons Attribution License, which permits unrestricted use, distribution, and reproduction in any medium, provided the original work is properly cited.

\begin{abstract}
Optimization of an air conditioning system is critical in terms of the transient and steady state behavior of the air distribution along the room and the temperature of the equipment themselves. In this paper, three computational techniques, namely, the standard $k-\varepsilon$, RNG $k-\varepsilon$, and the $k-\omega$ model, are used to numerically simulate and determine the air distribution in an air-conditioned room. The simulation results for all three methods are verified via a comparison with an experiment involving a room that contains a computer server which generates up to $6 \mathrm{~kW}$ of heat. In doing so and by additionally performing an error analysis, it is determined that the $k-\omega$ model produces the most accurate results. The results also indicated that the direction of air supply from the air conditioners has a strong impact on the velocity field and temperature distribution along the room and on the computer server. Hence, many candidate directions of air supply options were selected for study and by conducting a performance evaluation in terms of air temperature around the server, the optimal solution was obtained.
\end{abstract}

\section{Introduction}

The design of air-conditioning (AC) system is strongly dependent on the dynamics of the air flow in a room. Traditional measurement methods such as trial and error experiments is often time-consuming and expensive [1]. This is because modifying an existing AC system is generally a difficult and labor-intensive task and it is generally preferred that the optimal design be initially obtained in simulation. Therefore, computational fluid dynamics (CFD) are frequently adopted to design AC systems where the key benefits include reduced time and cost while retaining accurate and valuable results $[2,3]$. Moreover, CFD methods also have the advantages of enabling interactive visualization and repeatability [4]. Hence, CFD techniques are currently widely used in air distribution research and subsequently the design of $\mathrm{AC}$ systems [5-7].

With reference to other cases, literature studies show that the CFD simulations could be conveniently applied to analyze and predict the indoor air distribution $[4,8,9]$, to optimize the heating and cooling performances of the $\mathrm{AC}$ system [10,11], to evaluate the indoor thermal comfort
[12] or to take into account ammonia concentration for livestock [13]. In [14], air conditioning in a museum was studied with a coupled numerical approach of energy and fluid-dynamic analysis. Fariborz $\mathrm{H}$ and Chérif MA [15] comprehensively analyzed the validation of two models: COMIS and CONTAM. Furthermore, Li Y and Nielsen PV [16] discussed the major challenges of CFD and finally suggested that CFD technology has not become a replacement for experiment and theoretical analysis in ventilation research and rather it has become an increasingly important partner.

Indeed, because indoor airflow typically involves turbulent dynamics, a turbulence model will be required in the associated CFD simulation. A comparison of various types of $k-\varepsilon$ models including standard, renormalization group (RNG), low Reynolds number, and other types was conducted in [17] for analyzing natural and forced convection of indoor air flows. It was concluded that none of the models could accurately simulate anisotropic turbulence or secondary recirculation air dynamics. Alternatively, $[18,19]$ performed a literature survey on various existing turbulence models (including the various $k-\varepsilon$ models 
aforementioned) and concluded that there is no model that is universally optimal for any scenario and that the appropriate model is often application specific. More recently, [20] conducted another research on comparing 11 different turbulence models including Reynolds averaged numerical simulation (RANS) models for the wind tunnel application with comparisons to experimental results. They showed that the S-A model and the RNG $k-\varepsilon$ were the most suitable candidates for predicting surface pressure distributions but emphasized that they were unable to evaluate the most appropriate model for predicting turbulence length scales.

Indeed, CFD techniques and turbulence model are well established for simulation air flow distributions in various applications. However, although a comparison of adopting different turbulence models for analyzing natural and forced convective air flow or flow through test samples in wind tunnels currently exists in literature, this is not the case for an air-conditioned room that has a large heat source, a scenario that is commonly encountered in a computer server room. Therefore, this paper analyzes the air distribution of an air-conditioned room that specifically contains an operating computer server that generates up to $6 \mathrm{~kW}$ of heat. The temperature of air leaving the air conditioner is set to a reference value and the resulting air temperature and pressure dynamics are calculated via the CFD simulation. Three different turbulence models, the standard $k-\varepsilon$, RNG $k-\varepsilon$, and the $k-\omega$ model, are used to analyze the scenario and their accuracy is determined by an experiment involving a real computer server room with temperature measurements. Moreover, the effects of the different air supply directions on air distribution were analyzed in this work and the optimal configuration was determined based on evaluating the AC system's cooling rate and energy efficiency.

\section{Method and Governing Equations}

Several methods are available for studying the indoor air distribution, such as the traditional measurement and the method of numerical simulation based on the computational dynamics fluid (CFD). In this paper, we adopted the Fluent as the research tool and chose UDF to impose the boundary conditions. The standard wall function was adopted in this work to simulate the flow in the near-wall region, and the SIMPLE algorithm is used to couple the pressure and velocity. To simplify the problem, assumptions are made as follows $[4,21]$ :

(i) The air is steady turbulent flow;

(ii) Indoor air is incompressible and conforms to Boussinesq hypotheses; namely, changes of fluid density have an influence on buoyancy lift only;

(iii) Considering the room simulated is with good air tightness, so air leakage effect is out of consideration;

(iv) Indoor air is the Newton fluid, and its viscosity is isotropic;

(v) Ignore the energy dissipation caused by the viscous effect in the energy equation; (vi) Due to the adjacent houses, all equipped with air conditioning, interior wall and floor can be regarded as adiabatic boundary condition without temperature difference.

Reynolds time-averaged control equations with Boussinesq approximation are adopted in this work. By the assumptions above, the governing equations are as follows:

$$
\begin{gathered}
\frac{\partial \overline{\bar{u}_{i}}}{\partial \mathrm{x}_{i}}=0 \\
\rho \frac{\partial \overline{u_{i}}}{\partial t}+\rho \overline{u_{j}} \frac{\partial \overline{u_{i}}}{\partial x_{j}}=-\frac{\partial \bar{p}}{\partial x_{i}}+\mu \frac{\partial^{2} \overline{u_{i}}}{\partial x_{j} \partial x_{j}}-\rho \frac{\partial \overline{u_{i}^{\prime} u_{j}^{\prime}}}{\partial x_{j}}+\rho \overline{f_{i}},
\end{gathered}
$$

where $\overline{u_{i}}$ is Reynolds mean velocity in $i$ direction; $u^{\prime}$ is fluctuation velocity; $-\rho \partial \overline{u_{i}^{\prime} u_{j}^{\prime}}$ is Reynolds stress; $\rho$ is fluid density; $\mu$ is kinematic viscosity; $p$ is pressure; and $f_{i}$ is unit mass force.

To compare and find a suitable simulation to this model, the numerical results of standard $\kappa-\varepsilon$, RNG $\kappa-\varepsilon$ and $\kappa-$ $\omega$ turbulence models are compared in this work, where for standard $\kappa-\varepsilon$, the $\kappa$ equation, and $\varepsilon$ equation are

$$
\begin{aligned}
\frac{\partial(\rho k)}{\partial t}+\frac{\partial\left(\rho k u_{i}\right)}{\partial x_{i}}= & \frac{\partial}{\partial x_{j}}\left[\left(\mu+\frac{\mu_{t}}{\sigma_{k}}\right) \frac{\partial k}{\partial x_{j}}\right]+G_{k}+G_{b} \\
& -\rho \varepsilon-Y_{M}+S_{k} \\
\frac{\partial(\rho \varepsilon)}{\partial t}+\frac{\partial\left(\rho \varepsilon u_{i}\right)}{\partial x_{i}}= & \frac{\partial}{\partial x_{j}}\left[\left(\mu+\frac{\mu_{t}}{\sigma_{\varepsilon}}\right) \frac{\partial \varepsilon}{\partial x_{j}}\right] \\
& +C_{1} \frac{\varepsilon}{k}\left(G_{k}+C_{3} G_{b}\right)-C_{2} \rho \frac{\varepsilon^{2}}{k} \\
& +S_{\varepsilon},
\end{aligned}
$$

where $\varepsilon$ is defined as

$$
\varepsilon=\frac{\mu}{\rho} \overline{\left(\frac{\partial u_{i}^{\prime}}{\partial x_{k}}\right)\left(\frac{\partial u_{i}^{\prime}}{\partial x_{k}}\right)}
$$

and the turbulent viscosity is expressed as

$$
\mu_{t}=\rho C_{\mu} \frac{k^{2}}{\varepsilon}
$$

where $G_{k}$ is turbulent kinetic energy product; $G_{b}$ is turbulent kinetic energy caused by buoyancy; $Y_{M}$ is influence of fluctuating expansion of compressible turbulence on total dissipation rate; $S_{k}$ and $S_{\varepsilon}$ are source terms depending on the conditions; $C_{i}(i=1,2,3)$ is an empirical constant. 
For the RNG $\kappa-\varepsilon$, the $\kappa$ equation and $\varepsilon$ equation are

$$
\begin{aligned}
\frac{\partial(\rho k)}{\partial t}+\frac{\partial\left(\rho k u_{i}\right)}{\partial x_{i}}= & \frac{\partial}{\partial x_{j}}\left[\left(\alpha_{k} \mu_{e f f}\right) \frac{\partial k}{\partial x_{j}}\right]+G_{k}+G_{b} \\
& -\rho \varepsilon-Y_{M}+S_{k} \\
\frac{\partial(\rho \varepsilon)}{\partial t}+\frac{\partial\left(\rho \varepsilon u_{i}\right)}{\partial x_{i}}= & \frac{\partial}{\partial x_{j}}\left[\left(\alpha_{\varepsilon} \mu_{e f f}\right) \frac{\partial \varepsilon}{\partial x_{j}}\right] \\
& +C_{1} \frac{\varepsilon}{k}\left(G_{k}+C_{3} G_{b}\right)-C_{2} \rho \frac{\varepsilon^{2}}{k} \\
& -R+S_{\varepsilon},
\end{aligned}
$$

where

$$
\mu_{\text {eff }}=\mu+\mu_{t}
$$

and $\mu_{t}$ is the same as in (4). $1 / \alpha_{k}$ is effective Prandtl number of turbulent kinetic energy; $C_{\mu}$ is effective Prandtl number of dissipation rate; for the high Reynolds number problem $C_{\mu}=0.00845$.

For the $\kappa-\omega$ turbulence model, the $\kappa$ equation and $\omega$ equation are

$$
\begin{gathered}
\frac{\partial}{\partial t}(\rho k)+\frac{\partial}{\partial x_{i}}\left(\rho k u_{i}\right)=\frac{\partial}{\partial x_{i}}\left(\Gamma_{k} \frac{\partial k}{\partial x_{j}}\right)+G_{k}-Y_{k}+S_{k} \\
\frac{\partial}{\partial t}(\rho \omega)+\frac{\partial}{\partial x_{i}}\left(\rho \omega u_{i}\right) \\
=\frac{\partial}{\partial x_{j}}\left(\Gamma_{\omega} \frac{\partial \omega}{\partial x_{j}}\right)+G_{\omega}-Y_{\omega}+S_{\omega},
\end{gathered}
$$

where $G_{\omega}$ is the kinetic energy produced by $\omega$ equation; $\Gamma_{k}$ and $\Gamma_{\omega}$ are the diffusion rates of $\mathrm{C}$ and $\mathrm{D}$, respectively; $Y_{k}$ and $Y_{\omega}$ are the effect of turbulence caused by diffusion; $S_{k}$ and $S_{\omega}$ are the source terms depending on the conditions and select the $\kappa-\omega$ model when setting up the boundary conditions.

\section{Modeling and Experimental Setup}

An air-conditioned room involving a small computer center in the Sun Yat-sen University is selected as the research subject for this paper. The airflow parameter distributions throughout this room will be analyzed. The computer room consists of three tables, a locker, a computer server, and its uninterruptable power supply (UPS). In this room, the air conditioning system consists of two separate air conditioners with $30^{\circ}$ placed at the back of the room, as shown in Figure 1. The dimension of the model are as follows:

(i) Door dimensions: $2.1 \mathrm{~m} \times 0.9 \mathrm{~m}$;

(ii) Locker dimensions: $1.8 \mathrm{~m} \times 0.45 \mathrm{~m} \times 1.8 \mathrm{~m}$;

(iii) Table dimensions: $3 \times 1.5 \mathrm{~m} \times 0.75 \mathrm{~m} \times 0.85 \mathrm{~m}$;

(iv) The computer server and its two associated equipment: $0.6 \mathrm{~m} \times 0.96 \mathrm{~m} \times 1.98 \mathrm{~m} ; 0.94 \mathrm{~m} \times 0.78 \mathrm{~m} \times$ $1.2 \mathrm{~m} ; 0.25 \mathrm{~m} \times 0.51 \mathrm{~m} \times 0.57 \mathrm{~m}$;

(v) Room dimensions: $7.20 \mathrm{~m} \times 6.70 \mathrm{~m} \times 2.75 \mathrm{~m}$;

(vi) Air conditioner: $0.60 \mathrm{~m} \times 0.35 \mathrm{~m} \times 1.86 \mathrm{~m}$;
3.1. The Model and Mesh Generation. The software of ANSYS ICEM CFD is adopted in this study to generate the model and its grid. In order to improve grid quality, local mesh refinement for special boundaries and smoothing are performed. Different mesh sizes have been used to check the grid in dependency. And after considering both accuracy and economics, the computational domain was meshed into around 9,090,502 cells as illustrated in Figure 2.

And in this paper, the treatment of the near wall boundary is to make $\mathrm{y}^{+} \sim 1$, where $\mathrm{y}+$ is the dimensionless distance to the wall. For the turbulent flow in the fully developed area of the solid wall, it can be divided into the near wall area and the turbulent core area. In this research we pay more attention to the flow in the near wall area. And the near wall area can be further divided into an adhesive bottom layer, a transition layer, and a logarithmic layer, and these layers are the relationship between the dimensionless velocity $\mathrm{u}+$ and $y+$. Generally, $y+$ of the viscous underlayer should approach 1.

3.2. Boundary Condition Settings. Before the numerical calculation, we classified the boundaries and measured the necessary parameters as follows:

(a) Inlet Air Temperature. To get the temperature variation curve, nine temperature sensors are uniformly distributed in the air inlet of air conditioner (see Figure 3). The functions of the average temperature curves are as follows:

Right Air-Conditioning

$$
f_{1}(t)=A_{0}+\sum_{i=1}^{5} A_{i} \cos (i \omega t)+\sum_{i=1}^{5} B_{i} \sin (i \omega t)
$$

where $f_{1}(t)$ is air temperature supplied from right air conditioner; $t$ is time; $\omega$ is angular frequency, $A_{0}=296.4, A_{1}=1.101$, $\mathrm{A}_{2}=-1.019, \mathrm{~A}_{3}=0.9897, \mathrm{~A}_{4}=0.3855, \mathrm{~A}_{5}=0.1527, \mathrm{~B}_{1}=0.5416, \mathrm{~B}_{2}=-$ $0.6437, \mathrm{~B}_{3}=-0.741, \mathrm{~B}_{4}=-0.3257, \mathrm{~B}_{5}=-0.1593$, and $\omega=0.07797$.

\section{Left Air-Conditioning}

$$
f_{2}(t)=A_{0}+\sum_{i=1}^{6} A_{i} \cos (i \omega t)+\sum_{i=1}^{6} B_{i} \sin (i \omega t)
$$

where $f_{2}(t)$ is air temperature supplied from left air conditioner; $t$ is time; $\omega$ is angular frequency, $\mathrm{A}_{0}=300.1$, $\mathrm{A}_{1}=6.145, \mathrm{~A}_{2}=-1.242, \mathrm{~A}_{3}=-3.669, \mathrm{~A}_{4}=-1.542, \mathrm{~A}_{5}=0.3772$, $\mathrm{A}_{6}=0.3574, \quad \mathrm{~B}_{1}=-5.895, \quad \mathrm{~B}_{2}=-6.146, \quad \mathrm{~B}_{3}=-1.3, \quad \mathrm{~B}_{4}=2.122$, $\mathrm{B}_{5}=1.671, \mathrm{~B}_{6}=0.3795$, and $\omega=0.06637$.

(b) Inlet Air Velocity. The average air velocity of right air conditioner is $3.37 \mathrm{~m} / \mathrm{s}$ and that of left air conditioner is 3.88 $\mathrm{m} / \mathrm{s}$.

(c) Inlet Air Temperature of Server. The exhaust air temperature from server varies over time, but it fluctuates little. Therefore, we take an average temperature of $303.85 \mathrm{~K}$. 


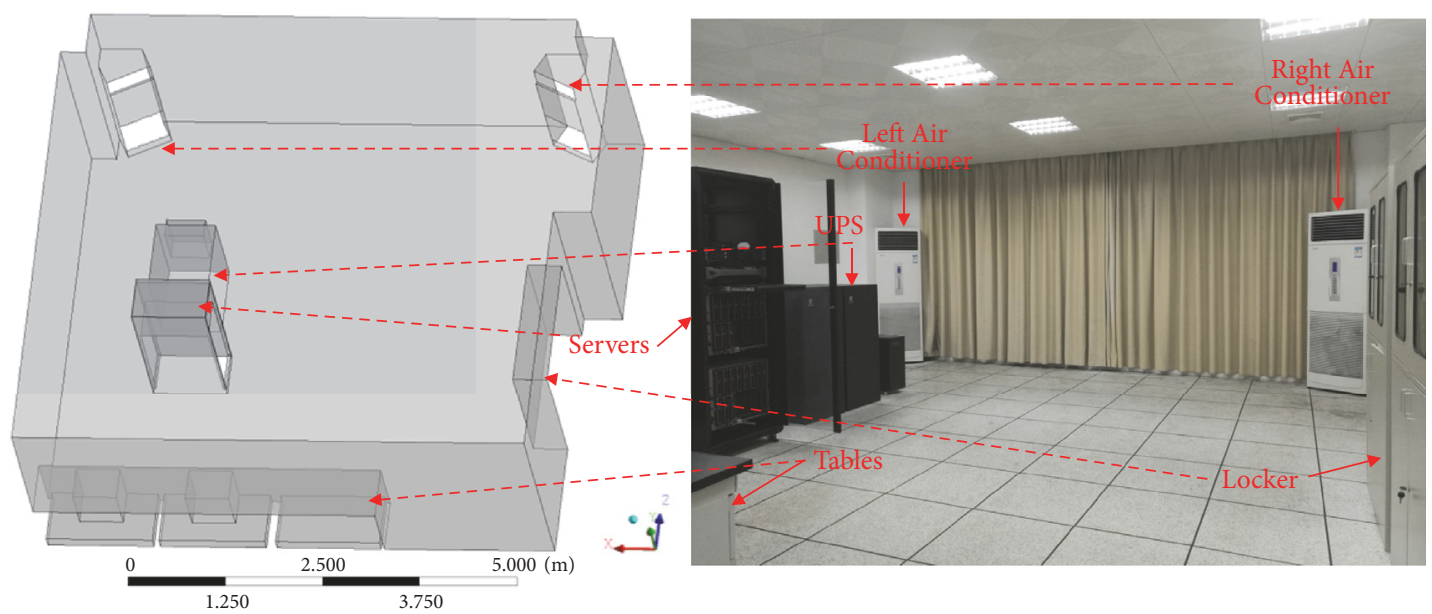

FIGURE 1: Schematic of the server room to be air conditioned.

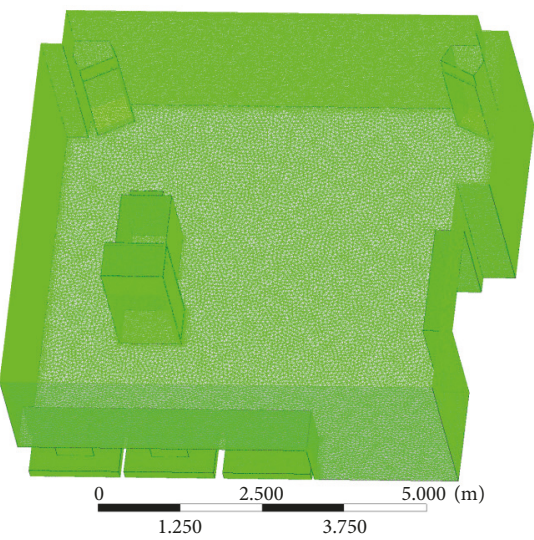

FIGURE 2: Surface mesh generation.

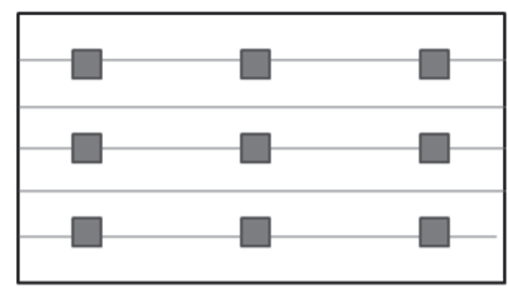

Figure 3: The distribution of sensors in the inlet.

(d) Inlet/Outlet Air Speed of Server. It is assumed that the speed of the cooling air entering the server equals the average velocity of air supplied from the server, which is $1.31 \mathrm{~m} / \mathrm{s}$.

(e) Initial Indoor Air Temperature: $303.65 \mathrm{~K}$. The simulation is based on the preset operation conditions. And these conditions are set according to the measurement data. As is shown in Figure 1, the air supply outlets of air conditioners and server are set as the speed inlets. The return air inlets are set as the opening-outlet boundaries with the temperature of $298 \mathrm{~K}$. And the front plane of the server is set as the speed outlet. The other boundaries are set to nonslip wall, wall insulation. Table 1 shows detail values of boundary conditions.

In order to study the influence of different air supply direction on indoor airflow, we consider nine different combinations of air flow supply directions from the two separated air conditioners and, for the sake of brevity, these shall be called air supply combinations. The configuration of each combination is shown in Table 2. In this table, 0 degree means parallel with respect to the ground. Also, positive values are facing upwards towards the ceiling and negative values are facing downwards towards the ground. The other parameters such as the supply air wind velocity are unchanged. 
TABLE 1: The preset operation conditions for simulation.

\begin{tabular}{lcc}
\hline Parameters & Value & Unit \\
\hline Inlet air velocity of right AC & $\mathrm{m} / \mathrm{s}$ \\
Inlet air velocity of left AC & 3.37 & $\mathrm{~m} / \mathrm{s}$ \\
Inlet air velocity of Server & 3.88 & $\mathrm{~m} / \mathrm{s}$ \\
Inlet air temperature of right AC & 1.31 & $\mathrm{~K}$ \\
Inlet air temperature of left AC & $f_{1}$ & $\mathrm{~K}$ \\
Outlet air temperature of right AC & $f_{2}$ & $\mathrm{~K}$ \\
Outlet air temperature of left AC & 298 & $\mathrm{~K}$ \\
Air temperature of server outlet & 298 & $\mathrm{~K}$ \\
Air temperature of server outlet & 303.85 & $\mathrm{~m} / \mathrm{s}$ \\
\hline
\end{tabular}

TABLE 2: Combinations of air supply direction.

\begin{tabular}{lcc}
\hline Operating conditions & Right air conditioning & Left air conditioning \\
\hline 1 & $+35^{\circ}$ & $+35^{\circ}$ \\
2 & $+35^{\circ}$ & 0 \\
3 & $+35^{\circ}$ & $-35^{\circ}$ \\
4 & 0 & $+35^{\circ}$ \\
5 & 0 & 0 \\
6 & 0 & $-35^{\circ}$ \\
7 & $-35^{\circ}$ & $+35^{\circ}$ \\
8 & $-35^{\circ}$ & 0 \\
9 & $-35^{\circ}$ & $-35^{\circ}$ \\
\hline
\end{tabular}

TABLE 3: Error analysis of the three turbulence models.

\begin{tabular}{lcc}
\hline Turbulence model & $\bar{E}$ & $\mathrm{U}$ \\
\hline$k-\varepsilon$ & 0.887 & 0.736 \\
RNG $k-\varepsilon$ & 0.890 & 0.864 \\
$k-\omega$ & 0.680 & 0.681 \\
\hline
\end{tabular}

\section{Result and Discussion}

4.1. Indoor Air Temperature Measurement. In order to analyze the accuracy of the results calculated by three turbulence models, we measured the temperature in the room. In this case study, the main way of the server cooling is that controlling the air temperature of the environment around the server. Therefore, after fully considering the influence of the air conditioning and the location of the main working zone (the server area), two rows of measuring sensors were set up at different height $(172 \mathrm{~cm}$ and $70 \mathrm{~cm})$ between the air conditioning and the server in the back of the room as shown in Figure 4(a). The area, in which the measuring sensors are located, is part of the working zone and close to the air conditioning with complicated airflow, and it has a certain representativeness. Figure 4(b) shows the detail distribution of the measuring points: the upper $(172 \mathrm{~cm})$ and lower $(70$ $\mathrm{cm})$ rows each contains five sensors.

4.2. Validation and Error Analysis. In this part, we presented the simulation results calculated by different turbulence models and discussed their accuracy by comparing the measurement data. This investigation used absolute calculation error and uniformity of errors to evaluate the accuracy with different turbulence models $[1,14]$.

The absolute calculation error is the difference between the simulation values with the turbulence models and the actual values, i.e.,

$$
E_{T i}=\left|v_{n i}-v_{m i}\right|, \quad i=1, \cdots, 10,
$$

where $E_{T i}$ represents the absolute error between the simulation temperature value and the actual value at sensor $i ; v_{n i}$ is the numerical simulation temperature value; $v_{m i}$ is the actual value.

The uniformity of errors evaluates whether or not different turbulence models would lead to an uneven simulation error distribution

$$
U=\sqrt{\frac{1}{N-1} \sum_{i=1}^{N}\left(E_{n i}-\bar{E}\right)^{2}},
$$

where $\mathrm{U}$ is the uniformity of errors for air temperature; $\mathrm{N}$ is the number of sensors, $E_{n i}$ indicates the simulation error of the air temperature at point $i$; and $\bar{E}$ is the averaged simulation error of the air temperature.

Table 3 lists the average simulation errors and the uniformity of errors for the flow domain, the working zone, calculated by (10) and (11), respectively. For the three turbulence models, with the same computational conditions, the $K-\omega$ model yielded a smaller average calculated error and higher uniformity than the others $[1,14]$. For the $k-\varepsilon$, RNG $k-\varepsilon$, and $K-\omega$ models the maximum relative calculated errors of the air temperature were $0.98 \%, 1.39 \%$, and $0.96 \%$, respectively. 


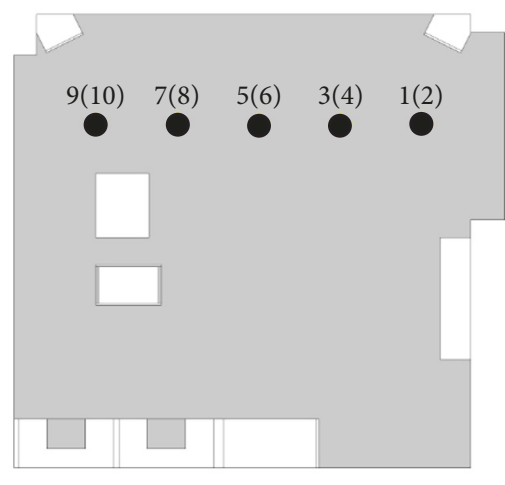

(a)

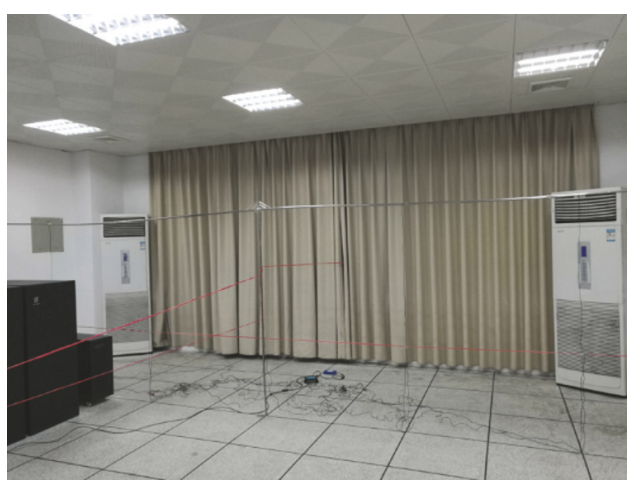

(b)

Figure 4: Measuring sensors distribution (a) and test scenario (b).

The errors of the three models are all in reasonable limits and the $K-\omega$ model performed best.

As shown in Figure 5, the errors between simulated values and measured values are different at different points. At the points $1,2,4,5,6,8$, and 10 , the simulated values of all the three turbulence models are well in agreement with the measured ones, whereas at the points 3,4 , and 9, the errors are bigger. It might result from the certain error between simulation results by the turbulence models and the real physical air distributions or the experimental instrument is not that precise. Generally, the simulation result of the $K-\omega$ model shows good agreement with the experimental findings with the error range from $0.006 \mathrm{~K}$ to $0.910 \mathrm{~K}$. And the RNG $k-\varepsilon$ and standard $k-\varepsilon$ models have similar performance. It should be noted that the biggest error appears at the point 3 and the calculation errors of the lower row measurement points $(70 \mathrm{~cm})$ were smaller. This difference arose because the airflow in the upper area $(172 \mathrm{~cm})$ is more complex and chaotic, so that it is more difficult to numerically calculate this area accurately.

In summary, it can be concluded that the $k-\omega$ turbulence model has the better reliability than that of the others in this study, and the simulation result can predict the real physic process. It must be pointed out that because of the grid generation, simplification of the physical model, computational method, and other factors, the deviation between the simulated values and the measurement data is large $(>1.0 \mathrm{~K})$ at some measuring points. But on the whole, the numerically calculated results are reasonable and reliable.

4.3. Analysis of the Air Supply Direction. Based on the conclusion of last section, the $k-\omega$ model was used to simulate the air distribution for analyzing the influence of air supply direction. In this case study, the server heat dissipation is controlled by ambient temperature; that is, the environmental temperature affects the server cooling directly. Therefore, the streamline pictures and temperature field cloud pictures of typical cross section near the cooling windward side of server (at $\mathrm{X}=3.6$ ) were analyzed.

The parallel air supply direction of both air conditioners (condition 5 in Table 2) is applying now in this air-conditioned room. Therefore, in the following discussion we chose it as a reference. Figures 6 and 7 show the pictures of streamlines and temperature fields cloud from condition 1 to condition 9, respectively. It could be observed that, different combinations of different air supply directions of two air conditioners have a significant influence on the fluid field and temperature distribution.

Due to the existence of a single the heat source (server) the original symmetrical the AC system is no longer symmetrical in the aspect of layout. That is why the obvious difference arose between the conditions, for instance, condition 2 and condition 4. As is shown in Figure 7, there are different situations of local higher temperature areas distribution and temperature stratification in the corner regions (mainly upper left) under all combination conditions. The main reason of this phenomenon is that, the high temperature air supplied from the server lifting and accumulating at the ceiling, and the exhausted air cannot be discharged in time. These partial hot spots could induce indoor heat island effect, which have adverse effects on indoor air organization and cooling efficiency $[22,23]$. In Figures $7(\mathrm{f})$ and $7(\mathrm{~h})$, the local high temperature areas under condition 6 and 8 are evidently larger than that under other conditions, and these areas even extend directly to the main working zone where the server located, namely, the area we concerned in this study (red circle in the figure). Meanwhile the phenomena of temperature stratification are more obvious under these conditions. Comparatively speaking, the temperature distribution of the main working zone is more uniform and there are fewer partial hot spots under the conditions 1,4 , and 7 $[24,25]$.

In order to optimize the air supply direction, we further analyzed the streamlines of conditions 1,4 , and 7 . As represented in Figure 6(a), there was no wide range recirculation and the air velocity distribution is also relatively uniform in the main working zone under the condition 1. But there were two small vortices near the server, which would increase the velocity gradient between the upper and lower regions. In Figure 6(d), it was found that the whole area is divided into different parts by the vortices, the streamlines were very messy, and there was a recirculation containing two vortices controlled the air organization near the server. And 


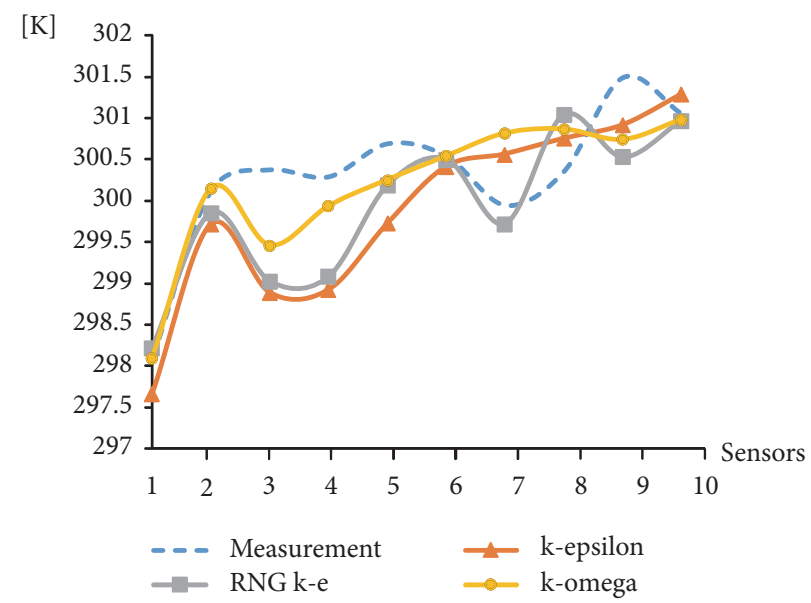

FIGURE 5: The comparison of simulation results and measurement.

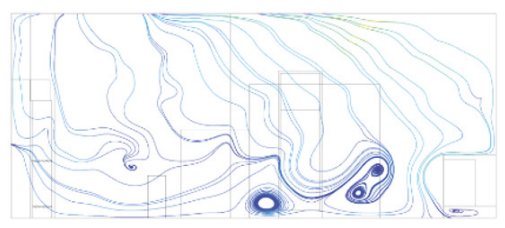

(a)

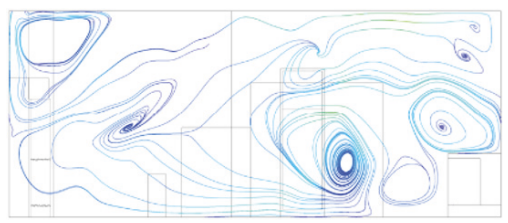

(d)

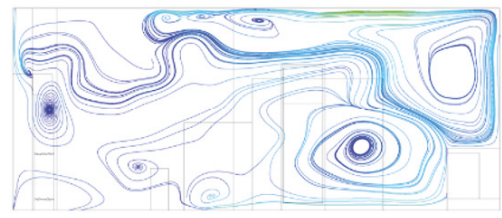

(g)

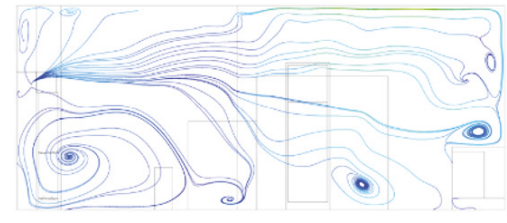

(b)

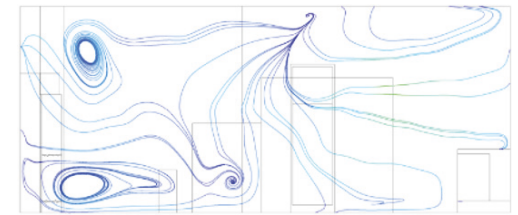

(e)

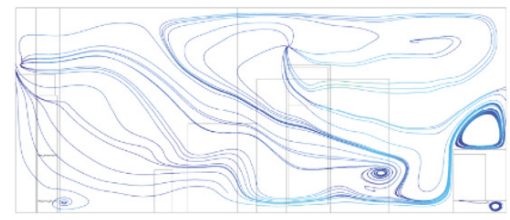

(h)

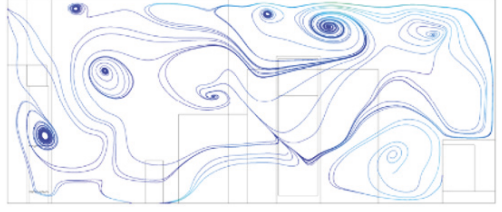

(c)

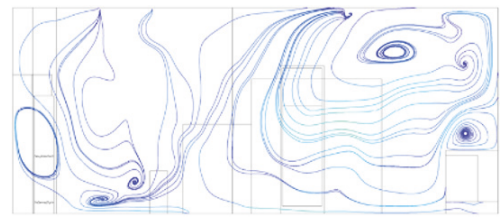

(f)

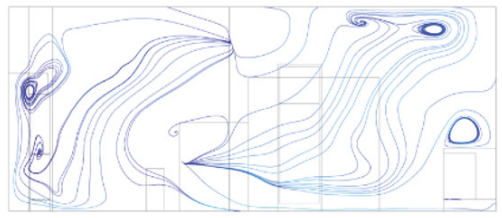

(i)

FIgURE 6: Streamlines, (a)-(i) corresponding the condition 1 to condition 9.

in Figure 6(g), air motion of the whole area was controlled by two large recirculation (upper and lower) containing two and four vortices, respectively. The recirculation moves along the surface of the enclosure structure and almost the entire working area is controlled by the bottom swing vortex. The velocity distribution, gradient, and the streamlines of the condition 7 perform better than that of the others.

Table 4 illustrates the different average cooling rates of the all conditions. The difference between all cooling rates is very small. We found that the maximum appearing in condition 4 is $0.032 \mathrm{~K} / \mathrm{s}$, the minimum is $0.022 \mathrm{~K} / \mathrm{s}$ for the condition 9 , and the cooling rate of condition 5 is $0.030 \mathrm{~K} / \mathrm{s}$.

In order to analyze the energy efficiency in the main working zone under different conditions, the energy utilization coefficient (EUC) that was adopted in $[26,27]$ is adopted here and is presented in

$$
\eta=\frac{T_{p}-T_{o}}{\bar{T}-T_{o}}
$$

where $\eta$ is the energy utilization coefficient, $T_{o}$ is the temperature of air supplied from the air conditioning, $T_{p}$ represents the temperature of the air returns to the air conditioners, and $\bar{T}$ is the average temperature of the air in working zone.

As regards this analysis, all the supply combinations have good performance on the energy utilization coefficient $(>1)$ $[21,26,27]$ except for the condition 9 (see Table 5). The best performance rose in the case of combination 2 (1.243) and the coefficient of condition 5 is 1.231. Furthermore, the difference 


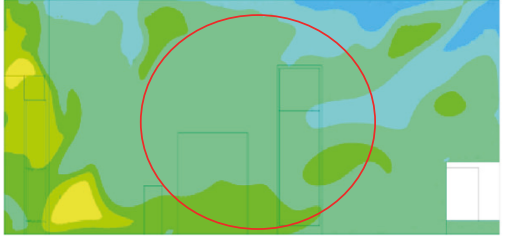

(a)

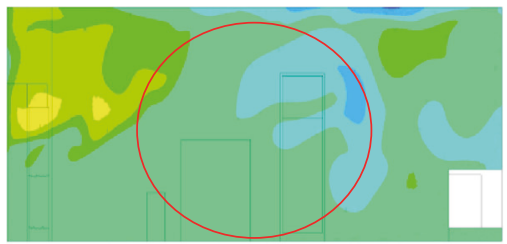

(d)

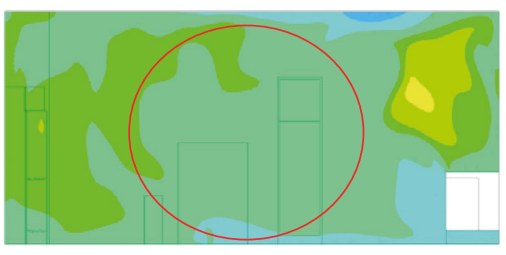

(g)

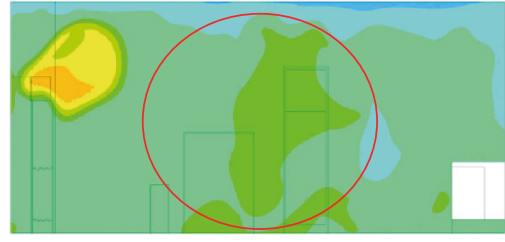

(b)

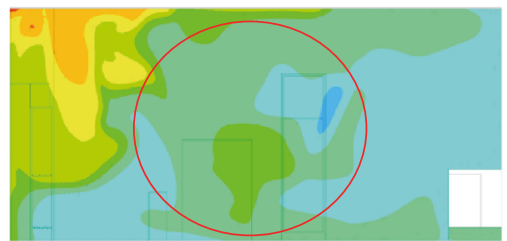

(e)

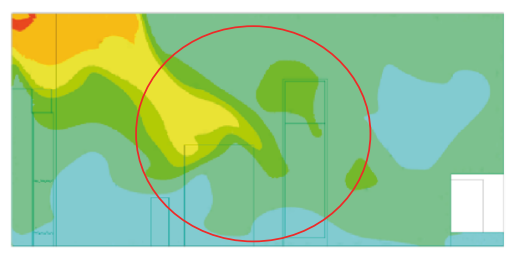

(h)

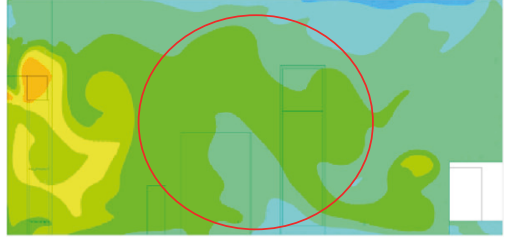

(c)

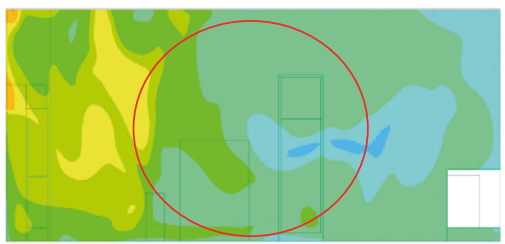

(f)

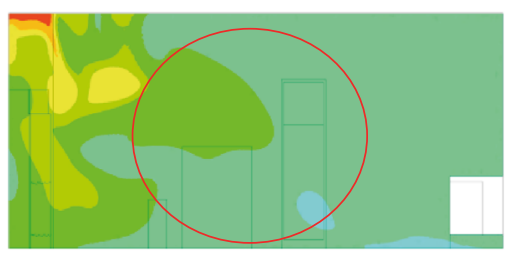

(i)

FIGURE 7: Temperature contour, (a)-(b) corresponding condition 1 to condition 9.

TABLE 4: Cooling rates of nine conditions.

\begin{tabular}{cccccccccc}
\hline & 1 & 2 & 3 & 4 & 5 & 6 & 7 & 8 & 9 \\
\hline Cooling rate (K/s) & 0.031 & 0.028 & 0.025 & 0.032 & 0.030 & 0.029 & 0.029 & 0.028 & 0.022 \\
\hline
\end{tabular}

TABLE 5: Energy utilization coefficient of different conditions.

\begin{tabular}{cccccccccc}
\hline & 1 & 2 & 3 & 4 & 5 & 6 & 7 & 8 & 9 \\
\hline$\eta$ & 1.165 & 1.243 & 1.042 & 1.222 & 1.231 & 1.0629 & 1.152 & 1.178 & 0.998 \\
\hline
\end{tabular}

among all conditions is quite small; namely, the air supply directions have a little influence on the energy utilization.

To sum up, in terms of the cooling rate, energy utilization coefficient, and the distributions of velocity and temperature, we discussed the influence of different combinations of air supply direction. The result shows that the AC system has defects. After a comprehensive analysis, we found that combination 7 has the best performance, so it is recommended that the air supply direction should be adjusted to the combination $7\left(-35^{\circ}\right.$ and $\left.+35^{\circ}\right)$ without changing the other settings.

\section{Conclusion}

In this paper, three turbulence models, namely, the standard $-\varepsilon$, RNG $k-\varepsilon$, and the $k-\omega$ model, were used to simulate air distributions for a conditioning room containing a high-powered computer server in CFD simulations. Several configurations of the air supply directions were studied and the results were all compared with that of a real experiment.
After performing a detailed evaluation of the obtained results, the following conclusions are obtained:

(1) By comparing the three studied turbulence models with that of the experimental results, it is found that the $k-\omega$ method produced the most accurate results. While the results of the standard $k-\varepsilon$ and RNG $k-\varepsilon$ were found to be similar, they were also found to have a larger relative error with respect to the experiment than that of the $k-\omega$ method where the relative errors are calculated to, be respectively, $0.983 \%, 1.393 \%$, and $0.96 \%$.

(2) By studying different air supply directions configurations, it is found that there is indeed a unique air supply directions combination that would provide the most stable velocity field and temperature distribution. In the scenario of this paper, it is found that combinations 7 and 8 (of Table 2) involved less vortices and turbulent flows, while in combinations 3 and 4 there are more chaotic and complex airflows. With regards to temperature distribution, combinations 4 and 7 were found to have much smoother temperature gradients than that of conditions 8 and 9. Overall, it can be 
concluded that there is certainly a unique combination of the air supply directions that provides the optimal velocity and temperature field distributions and this is found to be condition 7 (Table 2) for the scenario studied in this paper.

(3) In addition, the analysis in this paper also indicated that the air supply directions have little influence on the cooling rate and energy utilization coefficient. The maximum cooling rate is found to be $0.032 \mathrm{~K} / \mathrm{s}$ for combination 4 and the minimum one is $0.022 \mathrm{~K} / \mathrm{s}$ for the combination 9. In the meantime, the energy utilization coefficients ranged from 0.998 (for combination 9) to 1.243 (for combination 2).

\section{Data Availability}

The data used to support the findings of this study are available from the corresponding author upon request.

\section{Conflicts of Interest}

The authors declare that they have no conflicts of interest.

\section{Acknowledgments}

This work was partly supported by Key project of national key R\&D program for HPC under Grant no. 2016YFB0200603 and Special Program for Applied Research on Super Computation of the NSFC-Guangdong Joint Fund (the third phase) under Grant no. U1501501. The project of Guangzhou Science and Technology Program (Grant 655 no. 201704030089) also supports this research.

\section{References}

[1] Y. Huang, X. Shen, J. Li et al., "A method to optimize sampling locations for measuring indoor air distributions," Atmospheric Environment, vol. 102, pp. 355-365, 2015.

[2] J. F. Karlsson and B. Moshfegh, "Investigation of indoor climate and power usage in a data center," Energy and Buildings, vol. 37, no. 10, pp. 1075-1083, 2005.

[3] J. Cho, T. Lim, and B. S. Kim, "Measurements and predictions of the air distribution systems in high compute density (Internet) data centers," Energy and Buildings, vol. 41, no. 10, pp. 1107-1115, 2009.

[4] L. Yang, M. Ye, and B.-J. he, "CFD simulation research on residential indoor air quality," Science of the Total Environment, vol. 472, pp. 1137-1144, 2014.

[5] Z. Ma and S. Wang, "Building energy research in Hong Kong: A review," Renewable \& Sustainable Energy Reviews, vol. 13, no. 8, pp. 1870-1883, 2009.

[6] A. Foucquier, S. Robert, F. Suard, L. Stéphan, and A. Jay, "State of the art in building modelling and energy performances prediction: A review," Renewable \& Sustainable Energy Reviews, vol. 23, pp. 272-288, 2013.

[7] R. J. Dear, T. Akimoto, E. A. Arens et al., "Progress in thermal comfort research over the last twenty years," Indoor Air, vol. 23, no. 6, pp. 442-461, 2013.

[8] M. Cehlin, T. Karimipanh, and U. Larsson, "Unsteady CFD simulations for prediction of airflow close to a supply device for displacement ventilation," in Proceedings of the 13th International Conference on Indoor Air Quality and Climate, Indoor Air 2014, pp. 47-54, Hong Kong, July 2014.

[9] C. Huang, J. Lee, W. Yu, and W. Yu, "Study of the temperature flow field change by air-conditioning system in a indoor circular stadium," in Proceedings of the 2011 International Conference on Consumer Electronics, Communications and Networks (CECNet), pp. 3568-3571, Xianning, China, April 2011.

[10] X. Cui, K. J. Chua, and W. M. Yang, "Numerical simulation of a novel energy-efficient dew-point evaporative air cooler," Applied Energy, vol. 136, pp. 979-988, 2014.

[11] R. Qi and L. Lu, "Energy consumption and optimization of internally cooled/heated liquid desiccant air-conditioning system: A case study in Hong Kong," Energy, vol. 73, pp. 801808, 2014.

[12] D. Wang, Z. Zhang, L. Han, and L. Li, "Numerical simulation on air conditioning system and flow field of passenger compartment of type-A subway," Pain, vol. 152, no. 6, pp. 1317-1326, 2011.

[13] T. Norton, J. Grant, R. Fallon, and D.-W. Sun, "Assessing the ventilation effectiveness of naturally ventilated livestock buildings under wind dominated conditions using computational fluid dynamics," Biosystems Engineering, vol. 103, no. 1, pp. 78-99, 2009.

[14] F. Ascione, L. Bellia, and A. Capozzoli, "A coupled numerical approach on museum air conditioning: Energy and fluiddynamic analysis," Applied Energy, vol. 103, pp. 416-427, 2013.

[15] H. Fariborz and M. A. Chérif, "A comprehensive validation of two airflow models - COMIS and CONTAM," Indoor Air, vol. 6, no. 4, pp. 278-288, 1996.

[16] Y. Li and P. V. Nielsen, "Commemorating 20 years of Indoor Air: CFD and ventilation research," Indoor Air, vol. 21, no. 6, pp. 442-453, 2011.

[17] Q. Chen, "Comparison of different k- $\varepsilon$ models for indoor air flow computations," Numerical Heat Transfer, Part B: Fundamentals, vol. 28, no. 3, pp. 353-369, 1995.

[18] Z. J. Zhai, Z. Zhang, W. Zhang, and Q. Y. Chen, "Evaluation of various turbulence models in predicting airflow and turbulence in enclosed environments by cfd: Part 1-summary of prevalent turbulence models," HVAC\&R Research, vol. 13, no. 6, pp. 853870, 2007.

[19] Z. Zhang, W. Zhang, Z. J. Zhai, and Q. Y. Chen, "Evaluation of various turbulence models in predicting airflow and turbulence in enclosed environments by CFD: Part 2-comparison with experimental data from literature," HVAC\&R Research, vol. 13, no. 6, pp. 871-886, 2007.

[20] B. Li, J. Liu, F. Luo, and X. Man, "Evaluation of CFD Simulation Using Various Turbulence Models for Wind Pressure on Buildings Based on Wind Tunnel Experiments," in Proceedings of the 9th International Symposium on Heating, Ventilation and Air Conditioning, ISHVAC 2015 Joint with the 3rd International Conference on Building Energy and Environment, COBEE 2015, pp. 2209-2216, China, July 2015.

[21] J. Q. Yang and M. J. Li, "Numerical simulation of energy saving at different air supply angles in air-conditioned room," Applied Mechanics and Materials, vol. 385-386, pp. 263-267, 2013.

[22] A. Vukovic, "Data centers: Network power density challenges," ASHRAE Journal, vol. 47, no. 4, pp. 55-59, 2005.

[23] J. Rambo and Y. Joshi, "Modeling of data center airflow and heat transfer: State of the art and future trends," Distributed and Parallel Databases, vol. 21, no. 2-3, pp. 193-225, 2007. 
[24] Y. Maeda, Y. Seshimo, and T. Okazaki, "Study of a cooling system for the telecommunication base site," in Proceedings of the American Society of Heating, Refrigerating and AirConditioning Engineers, ASHRAE 2005 Annual Meeting, pp. 746-755, USA, June 2005.

[25] J. Choi, J. Jeon, and Y. Kim, "Cooling performance of a hybrid refrigeration system designed for telecommunication equipment rooms," Applied Thermal Engineering, vol. 27, no. 1112, pp. 2026-2032, 2007.

[26] N. Mao, M. Song, and S. Deng, "Application of TOPSIS method in evaluating the effects of supply vane angle of a task/ambient air conditioning system on energy utilization and thermal comfort," Applied Energy, vol. 180, pp. 536-545, 2016.

[27] D. Qi, L. Wang, and R. Zmeureanu, Large Eddy Simulation of Thermal Comfort and Energy Utilization Indices for Indoor Airflows, Ashrae Transactions, 2013. 


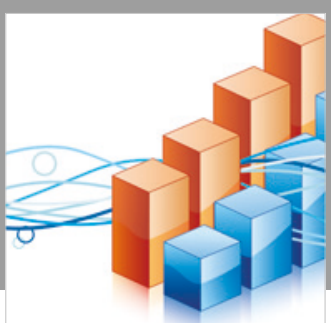

Advances in

Operations Research

\section{-n-m}
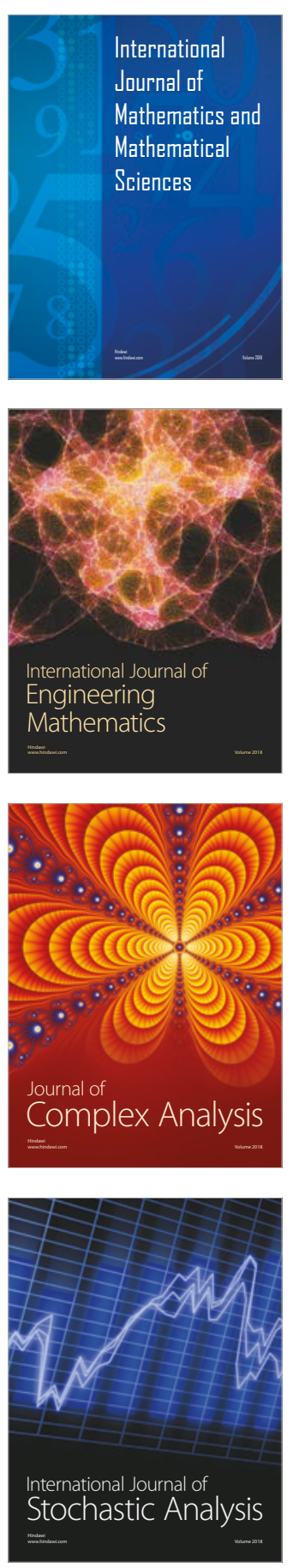
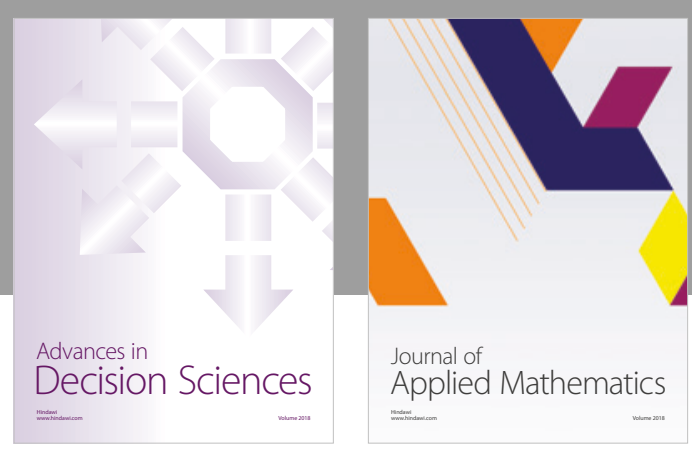

Journal of

Applied Mathematics
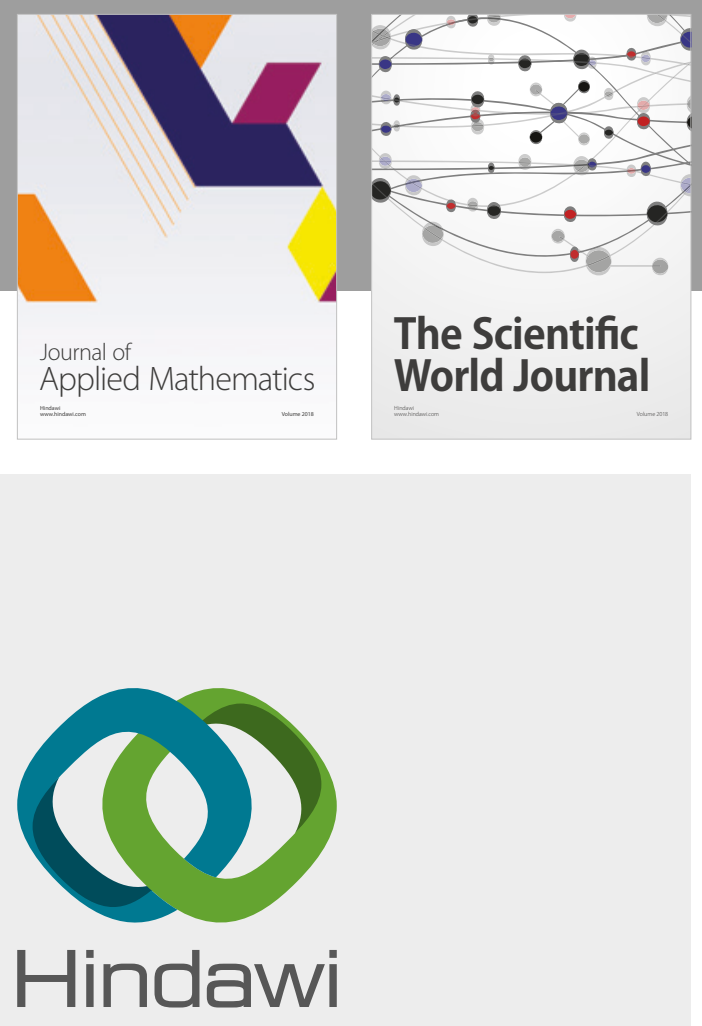

Submit your manuscripts at

www.hindawi.com

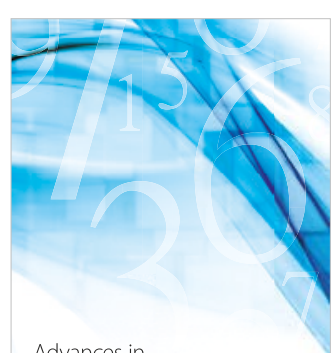

Advances in
Numerical Analysis
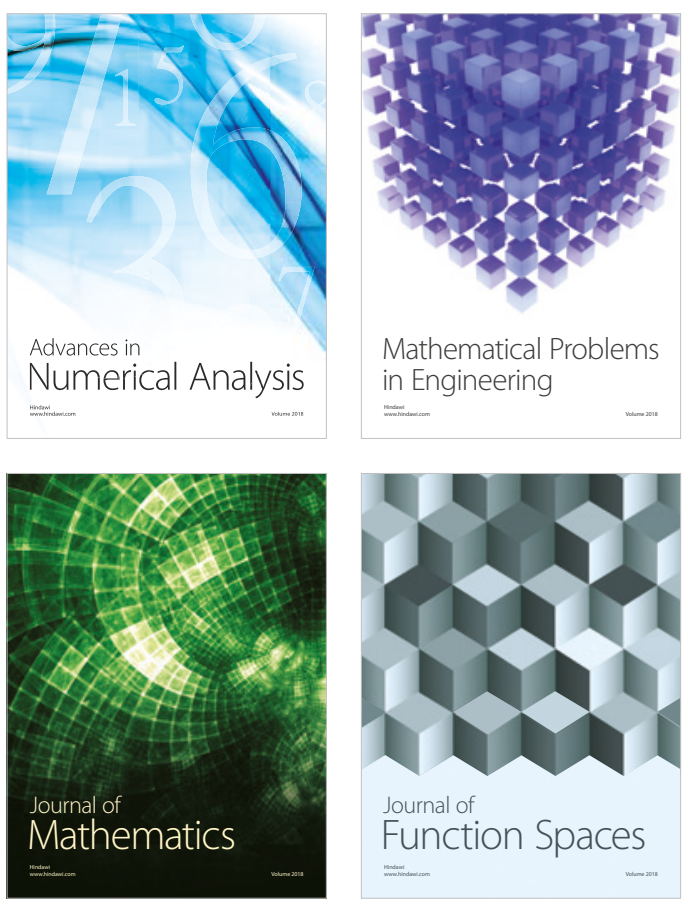

Mathematical Problems in Engineering

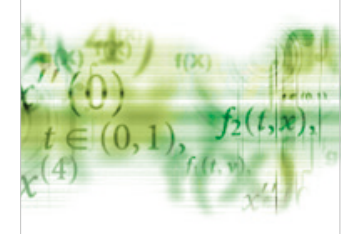

International Journal of

Differential Equations

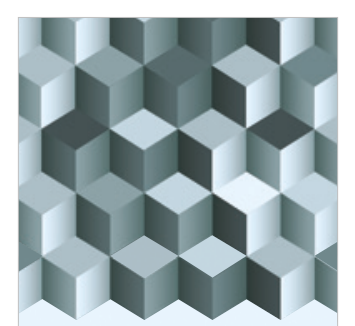

Journal of

Function Spaces

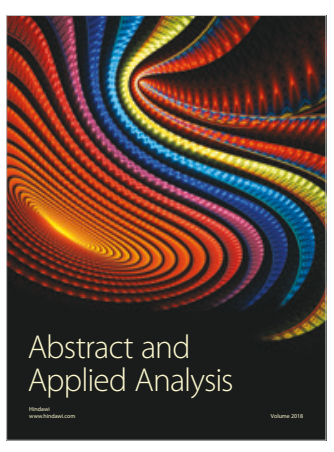

The Scientific

World Journal

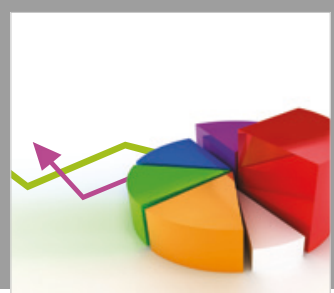

Journal of

Probability and Statistics
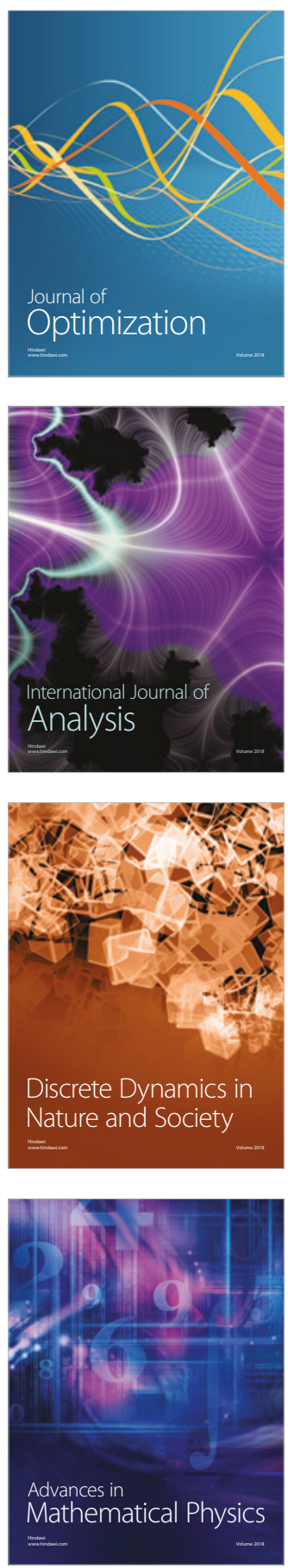